\title{
Para não espetacularizar o passado: memória, identidade étnica e educação patrimonial na construção do Memorial da Colônia Japonesa de Ivoti
}

\section{Resumo}

O estudo problematiza o processo de criação de um lugar de memória na Colônia Japonesa de Ivoti, no Rio Grande do Sul. Criado a partir da necessidade de registro da trajetória de 26 famílias japonesas que se instalaram em Ivoti, no ano de 1966, o Memorial da Colônia Japonesa apresenta-se aqui como objeto de investigação, inserindo-se no campo dos estudos sobre a patrimonialização e a educação patrimonial em comunidade. O memorial caracteriza-se como um espaço de salvaguarda e também um lugar de comunicação entre culturas e temporalidades, apresentando-se ainda como um produto turístico propulsor da economia local. O memorial configura-se a partir de um viés participativo, em cujas decisões a comunidade envolveu-se diretamente, desde o planejamento do espaço que o abrigaria, até a memória coletiva a ser escolhida, preservada e representada nesse lugar.

Palavras-chave: Memória. Identidade. Memorial. Educação Patrimonial.

\begin{abstract}
The present study argues the case of the process undergone for the creation of a memory place at the Japanese Colony located in Ivoti, Rio Grande do Sul. The Japanese Colony Memorial has been created due to the need of recording the trajectory run by 26 Japanese families who settled down in Ivoti in 1966. The referred Memorial is here taken under investigation as it is inserted in the study field concerning heritage and heritage education in a community. It is a safeguard site as well as a communication pool where different cultures and eras communicate. It is also a touristic product that fosters local economy. The participation of the local community has always been decisive for the configuration of the Memorial. All major decisions have been made collectively, from planning the space where the Memorial would be built to choosing the memory the community wished to preserve and represent.
\end{abstract}

Keywords: Memory. Identity. Memorial. Heritage Education.

\footnotetext{
${ }^{1}$ Graduada em História e mestranda do Programa de Pós-Graduação em Desenvolvimento Regional das Faculdades Integradas de Taquara - Faccat/RS. gabidilly@hotmail.com

2 Doutor em História e professor do Programa de Pós-Graduação em Desenvolvimento Regional das Faculdades Integradas de Taquara - Faccat/RS. danielgevehr@hotmail.com
} 


\section{Introdução}

O estudo analisa o processo de desenvolvimento de um projeto que envolveu a criação de um produto cultural e turístico, em uma comunidade conhecida como Colônia Japonesa de Ivoti (RS), localizada na Região Metropolitana de Porto Alegre, bastante próxima da serra gaúcha. O projeto envolveu um grupo de 45 famílias de origem japonesa, que, em geral, vive da agricultura familiar e que sempre despertou interesse cultural de quem visitava a cidade - conhecida principalmente pela presença da cultura herdada dos imigrantes alemães, que colonizaram a região no século XIX. Foi percebendo o interesse dos visitantes, que os moradores da Colônia Japonesa consideraram que seria importante preservar sua cultura, ou ainda mais, colocá-la "na vitrine" para que pudesse estar em interlocução com outras pessoas e culturas.

Além disso, o grupo encontrava-se em situação de "abandono cultural", não acreditando que, numa cidade onde há forte identidade cultural germânica estabelecida, pudessem também ser valorizados pela sua trajetória, bem como pelo valor de sua própria história, associada aos imigrantes japoneses. Essa situação indicava a rápida perda que acontecia em relação à memória oral do grupo, aos objetos de representação coletiva para o trabalho, a vida doméstica e os costumes diferenciados que o grupo sempre apresentou.

Dentro deste contexto de marginalidade cultural, foi estabelecido um projeto de educação patrimonial, na tentativa de manter vivas a memória e as tradições do grupo, ao mesmo tempo em que se procurou promover o desenvolvimento econômico para a comunidade, que passou a ser alvo das atenções dos visitantes, nos finais de semana, que para lá se dirigem em busca das comidas típicas, das festividades e da interação com a cultura nipônica.

Ivoti é um município situado no Vale do Sinos, no início da Serra - próximo de Nova Petrópolis, Gramado e Canela - que inicialmente era povoado por indígenas e, a partir do século XVIII, por colonizadores lusos. Em 1826, estabelecem-se ali as primeiras famílias de imigrantes alemães, inseridas no projeto da Antiga Colônia. Em 1964, Ivoti tornar-se-ia município e, a partir de 1966, receberia 26 famílias de imigrantes japoneses, vindos principalmente de Gravataí e Viamão.

Esses imigrantes buscavam um local no qual pudessem viver de forma associada, em cooperativa agrícola. Essa possibilidade surgiu em Ivoti, onde puderam adquirir 37 lotes de terras em unidade, formando a Colônia Japonesa de Ivoti. Para isso, contaram com a ajuda da Japan Agency Immigration Cooperation (JAMIC), instituição criada no Japão justamente em função da demanda populacional que emigrava após a 2a Guerra Mundial. A JAMIC auxiliava com linhas de crédito, para a compra de terras a juros baixos, além de oferecer um programa de medicina preventiva, com vacinas e visitas às casas. Também orientava os emigrantes através de publicações, como dicionários português/japonês, além de orientações sobre a fauna e a flora brasileiras. Através da JAMIC, emigraram moradores de várias regiões do Japão, como das províncias de Kagoshima-Ken, Kumamoto-Ken (ilhas ao sul do Japão), Hokkaido (ilha mais ao norte). A viagem de navio entre o Japão e o Brasil levava aproximadamente cinquenta e dois dias, e a partida acontecia no porto de Kobe. 
Inicialmente, tornou-se necessário organizar o espaço para a instalação das famílias e para o começo da produção agrícola. Cada família obteve em média cinco hectares de terra, e foram construídas casas de madeira, que serviram de moradia nos primeiros anos. Assim que foi possível, cada família construiu sua casa de alvenaria. Logo os japoneses constataram que o solo da área comprada era extremamente pobre e não oferecia, por si só, mais condições de render boas safras. Decidiram, então, iniciar seu trabalho colaborativo, abrindo um aviário, no qual poderiam comercializar as aves e também usar os dejetos como fertilizante das terras, recuperando-as. O grupo já tinha o propósito de cultivar uvas do tipo Itália.

A produção de uvas se tornou economicamente rentável, nos anos de 1970, período que foi de grande crescimento econômico na Colônia Japonesa. Nessa época, construíram casas melhores, galpões para armazenar e distribuir a produção, caminhões para o transporte da mercadoria. Também foi a época que os próprios membros da comunidade lembram como a "mais importante", quando, em 20 de fevereiro de 1969, foi constituída a Cooperativa Hortigranjeira Mista Ivoti Ltda, que tinha como finalidade fortalecer todos os produtores.

Ainda no início da década de 1970, aconteceram safras recorde de produção de uvas de mesa tipo Itália, as quais, em Ivoti, são chamadas de "uvas japonesas". No início dos anos 80, a produção de uvas passou a enfrentar concorrência, e seu preço caiu, assim como os lucros obtidos. A cooperativa que havia sido instituída teve problemas administrativos e não pôde sustentar o momento de crise. Para alguns, a solução foi mudar para a produção de hortaliças, mudas de hortaliças, flores de corte, kiwi e bergamotas tipo pokan. Infelizmente, para outros vários, a solução foi voltar para o Japão, principalmente os filhos homens dos imigrantes, que enviavam dinheiro para sustentar a parte da família que havia ficado no Brasil.

No que se refere aos seus aspectos culturais e sociais, vale ressaltar que a comunidade cultiva - e procura manter viva, com grande cuidado - suas tradições, fazendo até hoje comemorações milenares, como o Undou-kai (gincana esportiva) e o Enguei-kai (festival cultural). Há, no grupo, praticantes de Gateball (esporte semelhante ao cricket) e Softball (similar ao beisebol, mas numa versão mais "leve"). Há ainda a preocupação em preservar a técnica do origami, dobradura com papel. A festa de ano novo (shogatsu) também é um importante evento de integração de todos os moradores da Colônia, na qual é tradicionalmente feito o mochitsuki (bolinho de arroz em pasta). Na Colônia Japonesa de Ivoti, há ainda a prática de sumô e judô, além de uma escola de língua japonesa. Quem organiza este calendário de eventos é a Associação Cultural e Esportiva Nipo-Brasileira de Ivoti.

Hoje se percebe na Colônia Japonesa um movimento de retorno para a comunidade, principalmente após o período de crise no Japão. Com isso, os jovens estão voltando e diversificando os negócios da família.

\section{A memória, o patrimônio e as (re)invenções da Colônia Japonesa}

Com o propósito de compreender o processo que envolveu a construção dos lugares de memória - segundo Nora (1993) - da imigração japonesa, e, de forma especial, 
o processo que envolveu o trabalho de educação patrimonial na Colônia Japonesa de Ivoti, atentamos para aquilo que Halbwachs (2004) nos diz sobre os lugares de memória. De acordo com o autor, os lugares que percorremos cotidianamente nos fazem lembrar fatos do passado e, assim, contribuem para a construção da memória coletiva. Nesse contexto, a criação de museus, de monumentos e de lugares está diretamente associada a uma memória coletiva.

Nesse sentido, podemos lembrar aquilo que Stuart Hall (2014, p. 104) afirma, quando se refere às questões identitárias, produzidas pelos diferentes grupos sociais interessados. Para ele, "a identidade é um desses conceitos que operam 'sob rasura', no intervalo entre a inversão e a emergência: uma ideia que não pode ser pensada da forma antiga, mas sem a qual certas questões não podem ser pensadas". Seguindo essa interpretação, observamos que, no caso da Colônia Japonesa de Ivoti, operou-se a construção de uma identidade (étnica) para o lugar, na medida em que o passado dos primeiros imigrantes, chegados na localidade na década de 1960 , foi transformado no mito fundante da comunidade.

Destacamos em nossa análise os mecanismos envolvidos no processo de manipulação da memória (LE GOFF, 2003) e dos sentimentos coletivos dessa comunidade descendente de imigrantes japoneses, evidenciado a eleição dos símbolos e dos lugares de memória - materializados num lugar de memória que passa a ser visitado por aqueles "que vêm de fora". Observamos que é através dessa construção que se deu a materialização "das representações e dos sentimentos coletivos" (BRESCIANI; NAXARA, 2004) de seus primeiros imigrantes.

O imaginário presente nesse complexo processo de (re)elaboração do passado da comunidade, vale lembrar, tem como um de seus pontos de referência - e de lembrança - os lugares de memória, na expressão de Pierre Nora (1993, p. 25), para quem "a memória pendura-se em lugares assim como a história em acontecimentos".

A partir da criação de um lugar específico, para celebrar a memória da imigração japonesa em Ivoti, e que procura legitimar uma versão oficial sobre seu passado, atentamos para a análise feita por Françoise Choay (2001), para quem o patrimônio cultural produzido por uma comunidade serve também para advertir, ou lembrar, evocando, com isso, as emoções. Dessa forma, a cultura material e imaterial presente nesse espaço (oficial) de memória da comunidade procura respaldar determinadas visões e manter vivo, na memória da comunidade e também na de seus visitantes, o legado cultural dos primeiros japoneses que ali chegaram.

Ainda de acordo com a pesquisadora, a manutenção do patrimônio está alicerçada na ideia de conservação e recuperação da memória (CHOAY, 2001), fator que permite aos grupos sociais a manutenção da sua identidade individual ou coletiva. Assim, o "resguardo" de algum tipo de identidade ou de elementos simbólicos que estabelecem relações com essa identidade significa a manutenção de laços com os antepassados a um local, costumes e hábitos que demonstram quem são e de onde seus antepassados vieram.

Podemos conceituar o Patrimônio Cultural como um conjunto de bens de natureza material e imaterial que, por sua vez, são considerados coletivos e preservados durante o tempo. O Patrimônio Cultural comporta, ainda, os diferentes costumes de 
viver de um povo, transmitidos de geração a geração e recebidos por tradição, os quais, para se tornarem um Patrimônio, precisam ser reconhecidos e compartilhados pela comunidade que os produz. Como já afirmamos, o Patrimônio Cultural é dividido em duas categorias: os bens materiais e os bens imateriais. Segundo Feitosa e Silva (2011), os bens imateriais são todos aqueles relacionados à memória e às identidades e heranças de um povo ou nação, e o patrimônio cultural material é todo aquele que pode ser visto e tocado.

De acordo com a UNESCO, os bens imateriais são definidos como práticas, expressões, técnicas e conhecimentos que são transmitidos de geração em geração e são constantemente recriados pelas comunidades, que os reconhecem como parte integrante de seu grupo. Já para Rodrigues (2006), o patrimônio cultural é um conjunto de bens, materiais e imateriais, que são de interesse coletivo, perpetuados durante o tempo. Eles têm a função de relembrar acontecimentos tidos como importantes na memória social. Já para Tomaz (2010), o patrimônio deve ir além da mera concepção de bens materiais e imateriais, deve ser entendido como um processo social, formado através da dinâmica das experiências coletivas, que a coletividade preserva e transforma com tempo.

Dessa forma, podemos considerar o patrimônio cultural, seja material ou imaterial, como fruto da identidade de um povo. Ele representa tudo o que deve ser preservado, ou seja, tudo o que não deve ser esquecido, ainda que, na maioria das vezes, atendendo aos interesses de determinados grupos que o manipulam.

Associado à questão patrimonial apresentada por Choay (2001), percebemos que a identidade de um grupo pode ser compreendida como aquilo que diferencia o homem, a partir de suas ações e produções materiais, e marca, de modo mais especial, o passado. No caso do Brasil, com a Constituição Federal de 1988, foi possível dar visibilidade ao patrimônio, reconhecendo bens culturais e naturais, assim como dando legitimidade à preservação.

O Instituto do Patrimônio Histórico e Artístico Nacional (IPHAN) define que os Bens Culturais de Natureza Imaterial dizem respeito àquelas práticas e domínios da vida social que se manifestam em saberes, ofícios e modos de fazer, bem como em celebrações, formas de expressão cênicas, plásticas, musicais ou lúdicas e ainda em lugares como mercados, feiras e santuários que abrigam práticas culturais coletivas. O Patrimônio Cultural Imaterial, de acordo com o IPHAN (2014), é transmitido de geração a geração, constantemente recriado pelas comunidades e grupos em função de seu ambiente, de sua interação com a natureza e de sua história, gerando um sentimento de identidade e continuidade, contribuindo para promover o respeito à diversidade cultural e à criatividade humana.

Nesse sentido, a criação de memoriais - como é o caso da Colônia Japonesa de Ivoti - deve ser compreendida como uma categoria pertencente ao campo do patrimônio cultural material e imaterial, na medida em que incorpora em seus espaços saberes, modos de fazer, língua, tradições, religiosidade e também diferentes materialidades produzidas pelo grupo e transmitidas de geração em geração. Com isso, percebemos que os hábitos e as tradições de um povo nos dizem e revelam parte da sua cultura. Ainda, para Veloso (2006), o conceito de referência cultural ressalta o processo de produção e reprodução de um determinado grupo social e aponta para a existência de um universo 
simbólico compartilhado.

Neste contexto de discussão sobre o processo que envolve a atualização das memórias da comunidade nipônica de Ivoti, entendemos que os eventos promovidos por uma comunidade - como as festas promovidas para receber os turistas - podem ser de caráter popular, étnico, religioso, cultural e social, e geralmente retratam recortes do cotidiano e trajetórias históricas dos grupos que os produzem.

Esses recortes, como uma exposição em um memorial que faz referência ao passado dos imigrantes japoneses, podem ser compreendidos como um esforço coletivo que busca retratar aspectos da vida cotidiana da comunidade e que, a partir da criação desse lugar de memória, passa a representar elementos simbólicos da coletividade, que têm como elemento propulsor a etnicidade (POUTIGNAT; STREITFF-FENART, 1998). Com isso, tornam-se evidentes os propósitos presentes nesse processo de constituição dos lugares de memória, que também procuram criar algo único, que se torna particular, singular e reconhecível por aqueles que "olham de fora".

A constituição da identidade dessa comunidade não está ligada somente à sua origem étnica, mas também a outras práticas sociais, costumes, hábitos familiares e o próprio fazer das tradições (THOMPSON, 2013), as quais, por sua vez, são preservadas, atualizadas e (re)passadas (CANDAU, 2012) de geração em geração, com diferentes elementos, e que assim constituem o processo de construção de suas memórias e de suas identidades.

Com isso, a preocupação dos moradores da Colônia Japonesa de manter viva uma memória dos antepassados que colonizaram a localidade e que foi a principal responsável pela fundação dos pilares que deram origem à vida comunitária, passa, obrigatoriamente, por um processo de atualização da memória (CATROGA, 2011), por meio da qual a herança deixada pelos antepassados é ressignificada pelas atuais gerações.

A atualização dessa memória opera de tal forma que os ritos do passado se mantêm, mas são "atualizados" dentro de um novo contexto, no qual as tradições locais são mantidas, mas ressignificadas através das influências externas e das mudanças de comportamento do próprio grupo que as conduz. Sobre essa questão, acreditamos ser importante considerar Poutignat e Streiff-Fenart (1998, p.61), quando esses autores afirmam que "a primeira ingenuidade é acreditar que se pode definir uma unidade étnica (quaisquer que sejam os critérios utilizados para defini-la) por uma lista de traços". Em seguida, os autores citados, valendo-se dos estudos clássicos de Frederik Barth, afirmam que "Barth e seus colaboradores demonstram ser impossível encontrar um conjunto total de traços culturais que permitam a distinção entre um grupo e outro, e que a variação cultural não permite por si própria abranger o traçado dos limites étnicos". (Ibidem, p. 61) Assim, é evidente que, no caso da Colônia Japonesa de Ivoti, essas memórias e tradições étnicas também sofram transformações.

\section{0 projeto propulsor "Colônia Japonesa de Ivoti: um lugar para lembrar"}

Em 2009, iniciou-se o diálogo entre a administração pública municipal de Ivoti, através do Departamento de Cultura, e os representantes da diretoria da Associação da Colônia Japonesa de Ivoti, que resultaria no projeto denominado "Colônia Japonesa de 
Ivoti: Um lugar para lembrar". A primeira questão a definir era se a comunidade realmente queria um espaço de memória, um memorial, e, em caso de retorno afirmativo, onde instalá-lo e quem faria o projeto. Diante da resposta positiva, pois a comunidade apoiou a ideia e decidiu que o local escolhido para construção do memorial seria o prédio de uma antiga escola desativada na comunidade. De acordo com os representantes da comunidade, o responsável pela execução do projeto de reforma arquitetônica deveria ter vinculação étnica com a comunidade, decidindo-se, assim, pela arquiteta de origem nipônica Madalena Fuke.

O projeto foi levado duas vezes para aprovação da Associação e acolheu as contribuições dos moradores. Realizado o primeiro passo do projeto, criava-se, então, a proposta educativa, que objetivava fazer com que a comunidade percebesse seu potencial histórico, uma vez que ficou claro, pelo diagnóstico inicial, que os moradores não percebiam a si mesmos como sujeitos históricos. Ficou decidido que as estratégias de execução do projeto iriam primar pela participação dos moradores da Colônia Japonesa em todas as etapas. Existia, assim, a delicada tarefa de fazer com que o grupo realmente visse a si e a sua memória, na exposição final, em conjunto com o espaço arquitetônico.

Foram combinados, então, encontros com os moradores da colônia, que aconteciam na sede da Associação. O primeiro encontro discutiu o que seria este lugar de memória, como seria sua dinâmica de representação da história através dos objetos, a necessidade de ser seletivo, uma vez que não seria possível mostrar ali toda a trajetória daquelas famílias. Foi um encontro entre os conceitos de museu/memória/história, numa perspectiva acadêmica.

Os questionamentos iniciais foram sobre "o que queremos lembrar?", "como vamos contar nossa história?", "que acervo temos para mostrar?". Essa conversa inicial foi feita em etapas, para que, aos poucos, eles pudessem ir recompondo o quebra-cabeças de suas memórias. Também ficou estabelecido nesse encontro que o memorial deveria guardar, expor e comunicar elementos da memória coletiva, e não vaidades individuais. Ficou como "tarefa de casa", nesse encontro, revirar os sótãos, porões e galpões em busca de elementos significativos e representativos dessa coletividade.

No segundo encontro, procurou-se levantar mais detalhes, através da memória dos participantes. Questionou-se quais objetos, documentos, fotografias poderiam talvez possuir em casa que se relacionassem com a emigração do Japão, a aquisição das terras, os primeiros plantios, a construção das casas, as dificuldades iniciais, a organização das famílias, a criação da cooperativa. Também se buscou saber sobre os aspectos culturais, a alimentação, o esporte, o lazer, os festejos, a religião, entre outros elementos que foram surgindo.

Na sequência, buscou-se trabalhar com imagens, uma vez que a comunidade possuía quantidade expressiva de fotografias - elemento já conhecido como expressão dessa cultura. Foram projetadas mais de duzentas imagens que já haviam sido digitalizadas anteriormente. A proposta era sensibilizar, despertar memórias e selecionar o que era mais significativo, e que, posteriormente, iria ilustrar os painéis autoexplicativos da exposição.

O encontro mais polêmico foi aquele em que se definiu qual seria a história a ser contada, ou seja, aprovar um texto que falaria "sobre eles". Na ocasião, aconteceram 
diversas conversas em japonês, trazendo diferentes opiniões sobre o assunto. Um ponto era unânime: o destaque na exposição e na história do grupo seria a Cooperativa - que, para eles, era um símbolo do período mais próspero da Colônia Japonesa e do objetivo comum alcançado. Devido a isso, o único espaço de ambiência no Memorial reproduz uma sala de trabalho desse período. Decidiu-se ainda que o ideograma referente ao termo "união" seria exposto na entrada do memorial, complementando a mesma ideia central da exposição.

Posteriormente, os moradores da Colônia foram convidados a trazer objetos que considerassem pertencentes e representativos para a história da comunidade. Vieram muitas famílias com os mais diversos objetos, que hoje fazem parte do acervo do memorial.

Em novembro de 2011, o Memorial da Colônia Japonesa foi inaugurado, com a presença do Cônsul do Japão e do governador da província de Shiga, província japonesa coirmã do Rio Grande do Sul. Mais tarde, em 2012, o memorial incorporou o acervo presenteado pelas autoridades de Shiga ao governo do Rio Grande do Sul.

\section{A prática problematizada}

Num primeiro momento, o projeto apresentado levantou questões referentes à memória coletiva - elemento fundamental para a compreensão dos propósitos e do rigor metodológico empregado nas ações desenvolvidas nesse projeto de memória na Colônia Japonesa de Ivoti. Sobre ela - a memória coletiva - Halbwachs (2004), mais uma vez, contribui observando que esta coletividade precisa estar de acordo com a memória individual, a fim de que seja legitimada pelo grupo ao qual pertence, que, em nosso caso, é a comunidade de origem japonesa de Ivoti.

No projeto apresentado, foram feitos diversos encontros "despertadores de memórias", momentos em que a comunidade pôde se perceber como sujeito histórico (pouco provavelmente tenham se percebido dessa forma até aquele momento) e exercitar a busca por memórias, lembranças, tecidas ao longo do tempo e guardadas no arcabouço mental.

Essas memórias, para que venham à tona, precisam de tempo, de pistas que as conduzam para os momentos esquecidos, de vestígios que façam os sentidos relembrarem o que estava esquecido, adormecido ou dolorido. Esse "exercício do lembrar" fica mais rico quando as memórias individuais são contrapostas, discutidas coletivamente. Sobre essa relação entre a memória individual e a memória coletiva, Halbwachs (2004, p. 34) afirma que "para que nossa memória se auxilie com a dos outros, não basta que eles nos tragam seus depoimentos: é necessário ainda que ela não tenha cessado de concordar com suas memórias e que haja bastante pontos de contato entre uma e as outras", pois, segundo ele, somente assim a lembrança recordada pode ser reconstruída sobre um fundamento comum.

Essa mesma memória coletiva, por seu turno, é também elemento de constituição do sentimento de identidade (POLLAK, 1992), uma vez que ela explica, dentro de um contexto, a constituição ou reconstituição, sob o olhar do tempo atual, da pessoa sobre ela mesma. Em outras palavras, a pessoa se constrói em relação ao outro, e essa trajetória é expressa através das memórias que ela tem relacionadas ao grupo. 
Ainda sobre a memória do grupo pesquisado, é possível dizer que existem aquelas que ficaram suprimidas, que não vieram à tona. Sabe-se que as famílias da Colônia Japonesa de Ivoti passaram por momentos difíceis, quando a produção de uvas já não oferecia mais o retorno financeiro dos primeiros anos da década de 1970. Naquela situação de crise, aconteceram brigas entre vizinhos, parceiros de produção, instalou-se um mal-estar quanto à forma de administrar a Cooperativa instituída. Nada a esse respeito surgiu nas reconstruções das memórias dos mais velhos, somente os mais jovens falaram sobre isso - mas seus depoimentos não foram considerados ou comentados pelos mais velhos. O silêncio (RICCEUR, 2012) sobre esse aspecto foi evidente. É a seletividade da memória operando no grupo, que, segundo os estudos de Pollak (1989), podem apresentar zonas de sombra, de silêncios, ou o "não-dito".

Nos encontros entre os nipônicos, surgiram dilemas, dúvidas sobre como os fatos ocorreram, versões diversas da representação (CHARTIER, 2002) possível estabelecida pelo grupo. Chartier já discutiu amplamente as implicações que podem advir da necessidade de se estabelecer representações coletivas na história, e isso ficou muito claro neste projeto. A comunidade japonesa tem uma estrutura social que prioriza o respeito aos mais velhos, e foi a voz deles que prevaleceu nas decisões a respeito de "qual história" ficaria representada.

A discussão sobre reconstituição histórica foi instigada no grupo em um dos encontros, no qual se discutiu a impossibilidade de "demonstrar toda" história da comunidade. A pesquisa desenvolvida nos fez refletir sobre a intenção - muitas vezes latente - de muitas pessoas do grupo, que participaram do projeto de rememoração e reconstrução histórica, de querer contemplar "todos os aspectos de sua trajetória".

Diante disso, o grupo foi levado a aceitar a ideia de que não haveria como expor toda a coleção de objetos, a qual, mais tarde, seria doada ao acervo, primeiramente em função da impossibilidade física, ou seja, não haveria espaço suficiente, e também porque não haveria acervo que contemplasse todas as esferas históricas e nem memória que lembrasse todos os detalhes da história do grupo. Haveria, sim, a possibilidade de reelaborar uma parte da história coletiva que fosse significativa para o grupo, a partir dos vestígios históricos e das memórias que o grupo possuía hoje, relacionando o passado às necessidades do presente.

Mário Chagas (2014) estabelece uma relação importante entre os conceitos de passado, memória, presente e museu. Todas essas esferas, segundo o autor, encontramse no espaço museológico. O museu, numa perspectiva mais geral, além de ter o objetivo de reconstruir uma perspectiva possível do passado, precisa fazer isso se utilizando da tridimensionalidade: serão os objetos que, em primeira instância, precisarão estabelecer a comunicação.

Num primeiro momento, vamos estabelecer qual foi o entendimento das funções que deveria ter o Memorial da Colônia Japonesa. Em primeiro lugar, era clara a ideia de que ele deveria ser o espaço da discussão da trajetória histórica do grupo a ele relacionado, da reconstrução das versões possíveis e mutáveis das memórias relacionadas ao espaço museal.

Esse debate aconteceu antes mesmo de existir a exposição museográfica em si, sendo que essa exposição é fruto de escolhas e relações estabelecidas pela comunidade 
nipônica. Dentro dessa perspectiva, o objetivo era o de que as pessoas envolvidas no projeto percebessem a si mesmas como agentes da história, que a proposta levasse a todos o sentimento de coletividade e pertencimento. Para além dessa função, existia ainda a meta de utilizar o museu como alavancador de turismo cultural na comunidade, como fator de desenvolvimento econômico do local.

Dentro da história da Museologia, podemos demarcar algumas discussões importantes, momentos em que os conceitos sobre museus foram reestabelecidos a partir das perspectivas que se apresentavam na conjuntura social da América Latina. Um desses momentos cruciais foi a Mesa Redonda de Santiago do Chile, 1972, que inicia um movimento conhecido como Nova Museologia, segundo a qual "a função do museu passa a ser entendida para além da recolha e conservação de objectos, pois a instituição passa a ser vista como agente de desenvolvimento comunitário, exercendo um papel decisivo na educação da comunidade". (PRIMIO, 1999)

Nessa perspectiva, é possível perceber que o memorial da comunidade nipônica de Ivoti vem conseguindo ser um vetor de busca por alternativas de desenvolvimento social e econômico (social, dentro do que já foi abordado, e econômico no sentido de que já criou outros produtos culturais diretamente ligados a ele). A partir do estabelecimento do museu, a comunidade criou um evento mensal, uma feira, na qual são comercializados produtos artesanais, agrícolas e gastronômicos ligados à cultura japonesa. A feira vem obtendo bastante sucesso, oportunizando o desenvolvimento daquela comunidade e gerando o pleno exercício da cidadania.

Por meio do evento mencionado, o Museu amplia sua função de comunicador social. De nada adianta a criação de um memorial, se ele não tem a possibilidade de se comunicar, de estabelecer uma relação dialógica com quem o visita. A comunicação da exposição com o visitante é fundamental para que o museu exerça uma de suas maiores finalidades: ser vetor de discussão histórica, de mudança social.

Dessa forma, "a função museológica é, fundamentalmente, um processo de comunicação que explica e orienta as actividades específicas do museu, tais como a colecção, conservação e exibição do património cultural e natural" (ICOM, 1992). Daí decorre a ideia de que "os museus não são somente fontes de informação ou instrumentos de educação, mas espaços e meios de comunicação que servem ao estabelecimento da interacção da comunidade com o processo e com os produtos culturais" (Ibidem, 1992).

Nesse contexto, para atingir a finalidade de comunicar, o espaço museológico se utiliza de um projeto museográfico. Como a presente proposta não contou com a colaboração de um museólogo, a museografia do Memorial da Colônia Japonesa foi feita a partir das indicações dos participantes dos encontros de reconstrução histórica.

Nesses encontros, a comunidade apontou quais eram os pontos que considerava mais importantes na sua trajetória e que acervo tinha para representar estes momentos mais emblemáticos. Entre outros aspectos, ficou estabelecido que o período a ser reproduzido, representado, seria aquele em que os objetivos das famílias haviam se concretizado e, por isso mesmo, seria destacado na exposição. A forma encontrada para dar a devida relevância a este ponto foi a implementação de uma única ambiência no Memorial, que representa a Cooperativa, através de seu mobiliário, como podemos ver na Figura 1: 
Figura 1 - Ambiente da Cooperativa Agrícola no Memorial da Colônia Japonesa de Ivoti - RS

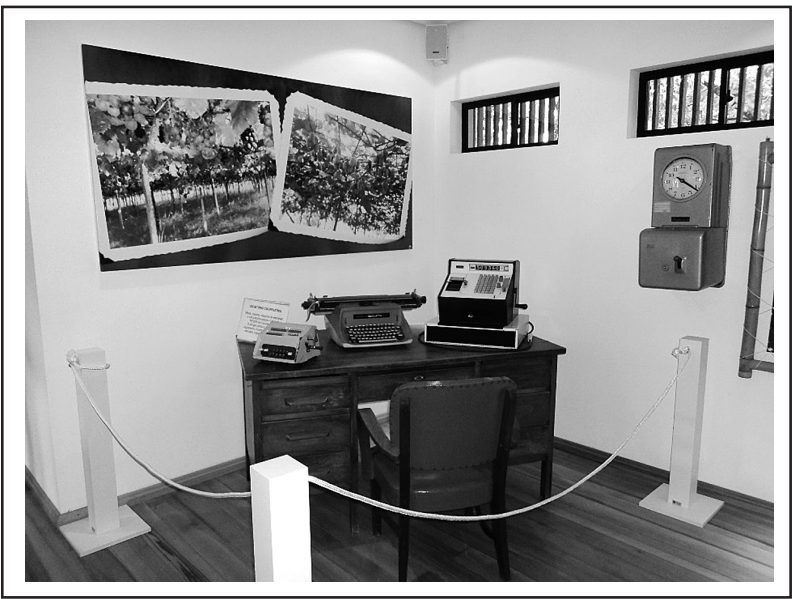

Fonte: Acervo pessoal.

Dentre o acervo doado ao Memorial, foi possível ainda destacar utensílios de trabalho na produção de uvas, elementos referentes à viagem dos imigrantes do Japão para o Brasil, objetos de uso doméstico e esportivo, vestimentas típicas, documentação e artesanato. Nas imagens a seguir, é possível visualizar a área interna inicial do Memorial.

Figura 2 - Perspectiva de quem entra pela porta lateral

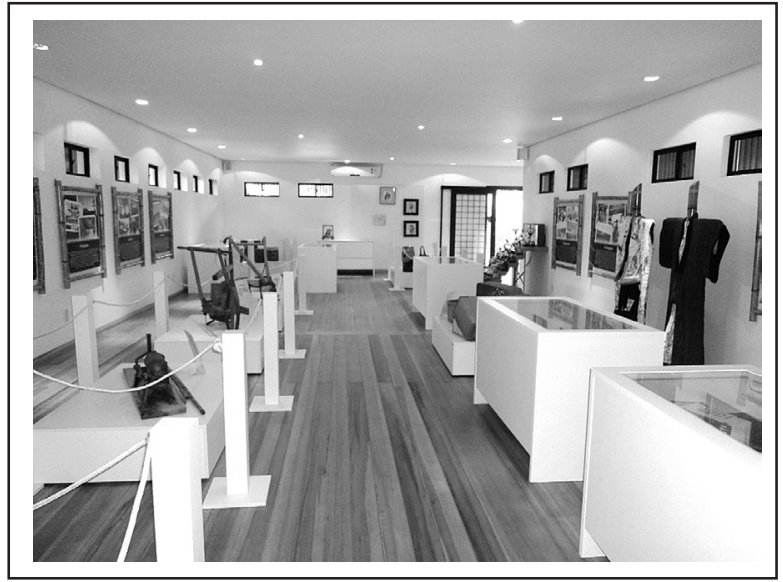

Fonte: Acervo pessoal. 
Figura 3 - Vitrine com aspectos da indumentária, acompanhada por manequins ao fundo

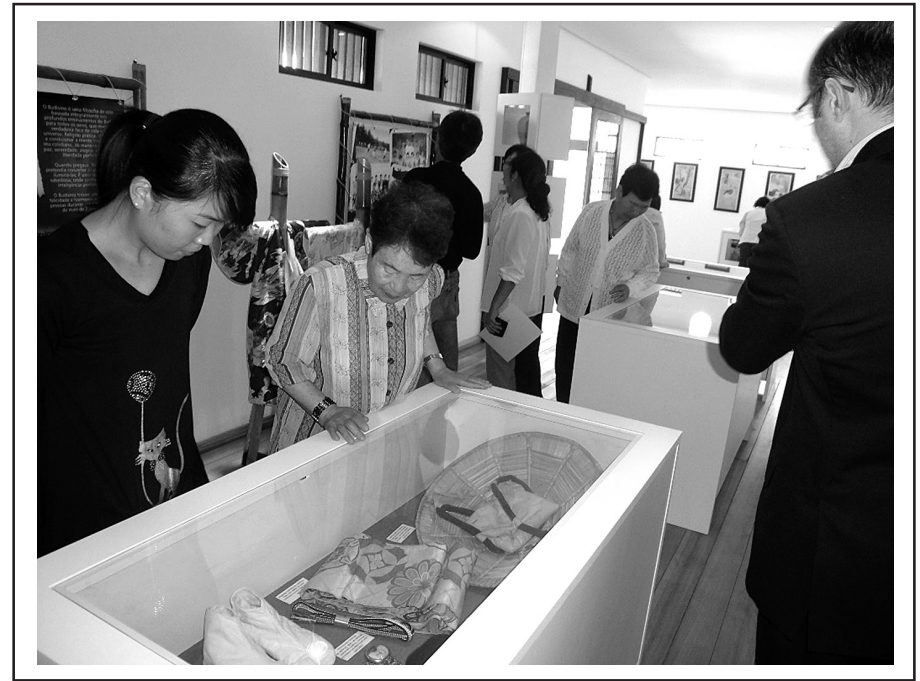

Fonte: Acervo pessoal (Foto feita por ocasião da primeira visita da comunidade ao museu).

O processo de doação de acervo é sempre um momento delicado. As pessoas precisam desapegar-se de um objeto seu, que muda de função, de acordo com a perspectiva. De acordo com Possamai (2010, p. 67), podemos identificar pelo menos três momentos em que os objetos passíveis de ir para o museu tomam significado. O primeiro, "de ordem subjetiva, é conferido pelo indivíduo a um determinado objeto, a ponto de garantir-lhe a preservação junto de si (afetivo, lembranças da infância, elo com mortos) pelo decurso de certo tempo". Já o segundo momento ocorre "quando passado um tempo mais prolongado, o detentor do objeto 'desconfia' do valor potencial do objeto como peça de museu, devido à observação de suas características de antiguidade, geralmente". O último momento se dá quando, "finalmente, quando ele é admitido no interior do museu, recebendo as significações do corpo funcional do museu, transformando-se em um dos objetos do seu acervo".

No caso da Colônia Japonesa de Ivoti, ficou claro para os doadores que seria feita uma escolha, uma seleção dos objetos que seriam expostos, de acordo com as temáticas que eles mesmos haviam indicado como importantes na representação material de sua história. Mesmo assim, sabe-se que "Expô-lo (o objeto) poderia significar, assim, para muitos doadores, tornar possível a relação do objeto com tudo aquilo que desejam evocar, sejam aspectos atinentes à sua própria vida ou à vida de outras pessoas, instituições ou grupos sociais" (POSSAMAI, 2010, p. 70). 
Figura 4 - Área externa do Memorial que complementa a museografia interna com jardim japonês para contemplação.

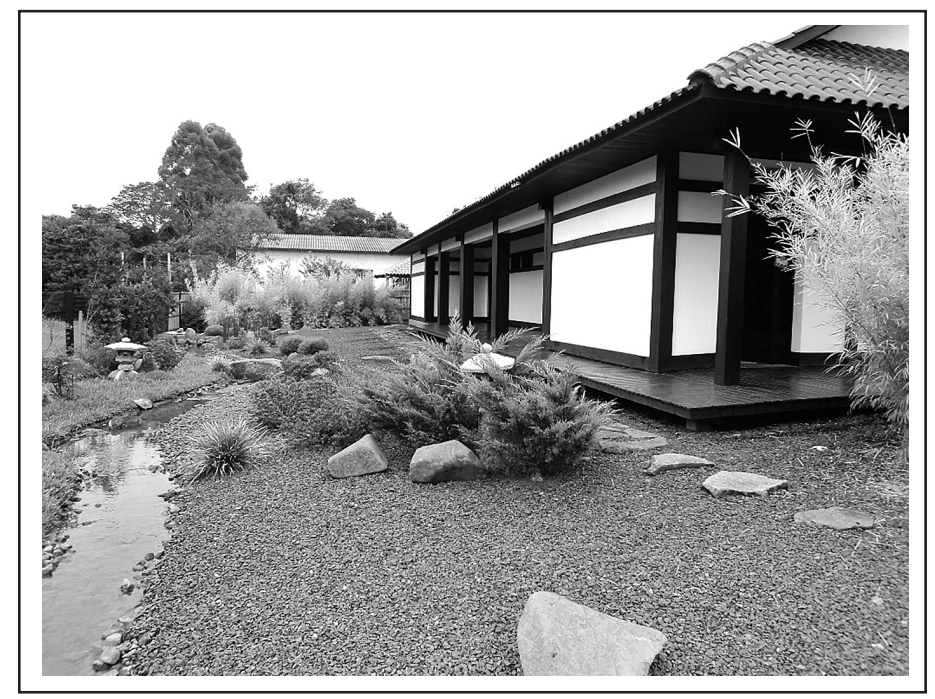

Fonte: Acervo pessoal.

Lidar com todas essas questões torna o espaço museológico um lugar de história viva, de testemunho, de dinâmicas de representações em vários níveis, numa riqueza de percepções e elementos que a palavra, sozinha, não consegue carregar.

Por fim, é necessário ainda problematizar o projeto na sua forma integral, compreendendo-o como uma iniciativa de educação patrimonial em comunidade. Leandro H. Magalhães (2009) define a educação patrimonial através de duas possibilidades: a tradicional, que homogeniza e universaliza memórias e que percebe apenas as manifestações que reforçam o status quo, e a transformadora, que possui uma visão crítica e é instrumento de descoberta e afirmação das identidades, além de se preocupar com a diversidade e o respeito às manifestações culturais.

Em nosso entendimento, o projeto desenvolvido na Colônia Japonesa se enquadra na categoria de transformador, uma vez que contou com a participação ativa da comunidade, que teve em mãos as diretivas das ações. A partir dela, fortaleceram-se a autoestima, a afirmação de identidade e o sentimento de pertencimento ao grupo, revelando-se como agente histórico reconhecido e valorizado no contexto social em que se insere.

É preciso ainda lembrar que o Memorial da Colônia Japonesa foi criado em projeto de Lei Municipal, que não pode mais ser revogado ou modificado, garantindo, assim, um espaço de reconstrução histórica constante para a comunidade a qual pertence.

\section{Considerações finais}

Ao planejar as ações educativas para a Colônia Japonesa de Ivoti, teria que se levar em conta o diagnóstico inicial: uma comunidade de adultos, em sua maioria idosos, 
desacreditados de seu valor histórico/cultural e em situação econômica vulnerável.

Foi necessário provocar o debate, mexer na dinâmica do grupo, desestabilizá-lo, mudar a perspectiva que aquelas pessoas tinham de si mesmas e de sua história. Além disso, como característica cultural, a comunidade nipônica demonstrava grande timidez, muito respeito aos mais velhos e reservas quanto a expor suas intimidades, sentimentos e histórias - muitas vezes de sofrimento - de suas famílias. O patrimônio cultural, suporte do trabalho educativo, precisava primeiro ser redescoberto, reapropriado pelos seus herdeiros.

A Colônia Japonesa de Ivoti apropriou-se de sua história em um processo participativo, delicado, no qual cada morador pôde contribuir com suas vivências, e o grupo lidou com suas memórias, dando-lhes forma, cor, volume, aroma - através dos objetos de representação que se estabeleceram.

Esse processo experimentado pelos moradores da Colônia Japonesa de Ivoti possa - talvez - ser traduzido nas palavras de Candau (2012, p. 159), para quem "a história do patrimônio é a história da construção do sentido de identidade e, mais particularmente, aquela dos imaginários de autenticidade que inspiram as políticas patrimoniais".

A comunidade da Colônia Japonesa de Ivoti fez de seu Memorial o espaço propulsor de valorização cultural, de sua identidade e de desenvolvimento para a comunidade. Todavia, a comunidade teve a preocupação de - em nenhum momento - espetacularizar seu passado, criando formas e objetos que não falassem deles próprios. Afinal, o Memorial deveria, segundo os anseios dos moradores da comunidade, representar seu passado da forma mais natural possível, para que esse passado se tornasse conhecido pelos visitantes.

\section{Referências}

BRESCIANI, Stella; NAXARA, Márcia (Orgs.). Memória e (res)sentimento: indagações sobre uma questão sensível. Campinas: Unicamp, 2004.

CANDAU, Jöel. Memória e identidade. São Paulo, Contexto, 2012.

CHARTIER, Roger. À beira da falésia: a história entre certezas e inquietudes. Porto Alegre: UFRGS, 2002.

CATROGA, Fernando. Os passos do homem como restolho do tempo: memória e fim do fim da história. 2. ed. Coimbra: Almedina, 2011.

CHAGAS, Mário. Memória e poder: contribuição para a teoria e a prática nos ecomuseus. Disponível em <http://www.quarteirao.com.br/pdf/mchagas.pdf>. Acesso em: 30 out. 2014.

CHOAY, Françoise. A alegoria do patrimônio. São Paulo: UNESP, 2001.

FEITOSA, Mônica Nascimento; SILVA, Sandra Siqueira da. Patrimônio Cultural imaterial e políticas públicas: os saberes da culinária regional como fator de desenvolvimento local. Salvador: UFBA, 2011. p. 193-208. 
GEVEHR, Daniel Luciano. Memórias de uma Colônia no sul do Brasil: o caso da Colônia Japonesa de Ivoti - RS. In: GERBER, Doris H. S. et al. (Org). Imigração: do particular ao geral. Ivoti/Porto Alegre: ISEI/CORAG, 2009. p. 99-104.

HALL, Stuart. Quem precisa da identidade? In: SILVA, Tomaz Tadeu da (Org.). Identidade e diferença: a perspectiva dos Estudos Culturais. 14. ed. Petrópolis: Vozes, 2014.

p. 103-133.

HALBWACHS, Maurice. A memória coletiva. São Paulo: Centauro, 2004.

ICOM. Declaração de Caracas, 1992. Disponível em:

<http://www.revistamuseu.com.br/legislacao/museologia/decl_caracas.asp>.

Acesso em: 0 nov. 2014.

IPHAN. Educação Patrimonial: histórico, conceitos e processos. Disponível em:

<http://www.iphan.gov.br/baixaFcdAnexo.do?id=4240>. Acesso em: 11 maio 2014.

LE GOFF, Jacques. História e Memória. 5. ed. Campinas: Unicamp, 2003.

MAGALHÃES, Leandro Henrique. Educação Patrimonial: Uma análise conceitual. In: ZANON, Elisa Roberta et al. (Org.). A construção de políticas patrimoniais: ações preservacionistas de Londrina, Região Norte do Paraná e Sul do país. Londrina: UniFil, 2009. p. 65-77.

NORA, Pierre. Entre memória e história. A problemática dos lugares. Projeto História, São Paulo, Revista do Programa de Pós-graduação em História e do Departamento de História PUCSP, n. 10, dez. 1993. p. 7-28.

POLLAK, Michael. Memória e identidade social. Estudos Históricos, Rio de Janeiro, v. 5, n. 10, p. 200-212, 1992.

. Memória, esquecimento, silêncio. Estudos Históricos, Rio de Janeiro, v. 2, n. 3, p. 3-15, 1989.

POSSAMAI, Zita Rosane. As artimanhas do percurso museal: narrativas sobre objetos e peças de museu. Revista Museion, v. 4, n. 7, p. 64-72, jan./jun. 2010.

POUTIGNAT, Philippe; STREITFF-FENART, Jocelyne. Teorias da Etnicidade seguido de Grupos Étnicos e suas Fronteiras de Frederik Barth. São Paulo: Unesp, 1998.

PRIMIO, Judite Santos. Pensar contemporaneamente a museologia. Cadernos de Sociomuseologia, n. 16, p. 5-38, 1999.

RICCEUR, Paul. A memória, a história, o esquecimento. Campinas: Unicamp, 2012.

RODRIGUES, Cíntia Nigro. Territórios do patrimônio: tombamentos e participação social na cidade de São Paulo. 2006. 256 f. Dissertação (Mestrado em Geografia) - Universidade de São Paulo, São Paulo, 2006. 
TOMAZ, Paulo Cesar. A preservação do patrimônio cultural e sua trajetória no Brasil. Fênix - Revista de História e Estudos Culturais, ano VII, v. 7, n. 2, maio/ago. 2010.

THOMPSON, E. P. Costumes em comum: estudos sobre a cultura popular tradicional. São Paulo: Cia. das Letras, 2013.

VELOSO, Mariza. O Fetiche do Patrimônio. Revista Habitus, Goiânia, v. 4, n. 1, jan./jun. 2006. p. 437-454. 